\title{
Specificity of the volume-activated amino acid efflux pathway in cultured human breast cancer cells
}

\author{
David B. Shennan and Jean Thomson \\ Strathclyde Institute of Pharmacy and Biomedical Sciences, University of Strathclyde, Royal College, Glasgow, United \\ Kingdom
}

\begin{abstract}
It has been shown that cell swelling stimulates the efflux of taurine from MCF-7 and MDAMB-231 cells via a pathway which has channel-like properties. The purpose of this study was to examine the specificity of the volume-activated taurine efflux pathway in both cell lines. A hyposmotic shock increased the efflux of glycine, L-alanine, AIB ( $\alpha$-aminoisobutyric acid), D-aspartate but not L-leucine from MDA-MB-231 and MCF-7 cells. It was evident that the time course of activation/ inactivation of those amino acids whose efflux was affected by cell swelling was similar to that of volume-activated taurine efflux. The effect of exogenous ATP on swelling-induced glycine, AIB and D-aspartate efflux from MDA-MB-231 cells was similar to that found on taurine efflux. In addition, volume-activated AIB efflux from MDA-MB-231 cells, like that of swelling-induced taurine efflux, was inhibited by diiodosalicylate. Tamoxifen inhibited volume-activated taurine release from both MDA-MB-231 and MCF-7 cells. The results suggest that neutral and anionic $\alpha$-amino acids are able to utilize the volume-activated taurine efflux pathway in both cell lines. The effect of tamoxifen on breast cancer growth may, in part, be related to perturbations in cell volume regulation.
\end{abstract}

Key words: Taurine efflux - Breast cancer cells - Volume-regulation - Tamoxifen

\section{Introduction}

It is well established that cell volume rapidly changes as a consequence of solute accumulation, transepithelial transport and/or a hyposmotic challenge (Hoffmann et al. 2009). Cells need to offset large changes to their volume otherwise they could undergo osmotic lysis. In this connection, cells possess a variety of transport mechanisms which can be utilized to maintain the cellular hydration state within relatively narrow limits (Hoffmann and Simonsen 1989; Hoffmann et al. 2009). For example, it is well documented that cell swelling stimulates the release of $\mathrm{K}^{+}$and $\mathrm{Cl}^{-}$and osmotically-obliged water thus allowing cells to undergo a regulatory volume decrease (RVD). The efflux of amino acids, especially taurine, which is invariably the most abundant intracellular amino acid in mammalian cells, is also stimulated by cell swelling

Correspondence to: David B. Shennan, Strathclyde Institute of Pharmacy and Biomedical Sciences, University of Strathclyde, Royal College, 204 George Street, Glasgow, G1 1XW, United Kingdom

E-mail: Dtaurine@aol.com
(Huxtable 1992). On the basis that many cell types possess a large pool of free intracellular amino acids it is predicted that the efflux of amino acids may also make a significant contribution to a RVD (Hoffmann et al. 2009).

Although cells need to regulate their volume to avoid lysis, it has become apparent that cell volume per se is an important signalling mechanism and plays a prominent role in the regulation of protein, lipid and carbohydrate synthesis (Häussinger 1996; Millar et al. 1997; Lang et al. 1998). Moreover, there is also a growing body of evidence suggesting that cell migration, apoptosis and cell proliferation are all influenced by cell volume regulatory mechanisms (Maeno et al 2000; Trimarchi et al. 2002; Stutzin and Hoffmann 2006). Therefore it follows that a thorough understanding of the mechanisms which regulate cell volume could lead to strategies being developed to control the growth of cancer cells. In this regard, we and others have investigated the effect of cell swelling on the transport of ions and taurine in cultured human breast cancer cells. Human breast cancer cells, in common with other cell types, express mechanisms which facilitate a regulatory volume decrease. For example, cell swelling increases the efflux of $\mathrm{K}^{+}\left(\mathrm{Rb}^{+}\right), \mathrm{Cl}^{-}\left(\mathrm{I}^{-}\right)$and 
taurine from both MDA-MB-231 and MCF-7 cells (Horton et al. 1998; Gow et al. 2005; Marin et al. 2005; Shennan et al. 2006; vanTol et al. 2007; Roy et al. 2008). However, the molecular identities of all the pathways involved in breast cancer cell volume regulation are unknown with the exception of two $\mathrm{K}^{+}$channels, namely KCNQ1 and hERG (vanTol et al. 2007; Roy et al. 2008).

Volume-activated taurine efflux from human breast cancer cells is via a pathway sensitive to anion channel blockers such as DIDS and diiodosalicylate but it is evident that the pathway is distinct from $\mathrm{Cl}^{-}$channels (Shennan et al. 2006). At present, it is not known if the taurine channel in breast cancer cells is specific for taurine or also allows $\alpha$-amino acids to pass through. The specificity of the channel is important given that mammary tumour cells have a relatively large intracellular amino acid pool (Pine et al. 1982; Brodzki et al. 2004; Kao et al. 2010) which could be utilized to facilitate a RVD. The main purpose of the present study was to test the effect of a hyposmotic shock on the efflux of $a$-amino acids from MDA-MB-231 and MCF-7 human breast cancer cells which are respectively, estrogen receptor-negative and -positive. In particular, we wanted to determine whether or not $\alpha$-amino acids utilized the volume-activated taurine efflux pathway thus we have examined the effect of a hyposmotic shock on the efflux of AIB ( $\alpha$-aminoisobutyric acid), D-aspartate, L-alanine, glycine and L-leucine. In addition we have examined the effect of tamoxifen, a compound routinely used to treat patients with estrogen receptor-positive breast cancer, on swelling-induced taurine release from cultured breast cancer cells given that it has been reported that tamoxifen methiodide is able to increase the hydration state of MCF-7 cells (Paran et al. 2004).

\section{Materials and Methods}

\section{Cell Culture}

MDA-MB-231 and MCF-7 cells, purchased from the European Animal Cell Culture Collection, were cultured in Dulbecco's Modified Eagle Medium (DMEM) supplemented with L-glutamine $(2 \mathrm{mM})$, heat-inactivated fetal bovine serum $(10 \%)$, penicillin $(50 \mathrm{IU} / \mathrm{ml})$ and streptomycin $(50 \mu \mathrm{g} / \mathrm{ml})$. Cells were grown in a gas phase of air with $5 \% \mathrm{CO}_{2}$ at $37^{\circ} \mathrm{C}$. MDA-MB-231 and MCF-7 cells were seeded in $35 \mathrm{~mm}$ culture wells containing $2 \mathrm{ml}$ of culture medium and were used when they had reached $60-90 \%$ confluency.

\section{Amino acid efflux}

The efflux of taurine, AIB, D-aspartate, L-alanine, glycine and L-leucine was measured from MDA-MB-231 and
MCF-7 cells using a modification of the method described by Shennan et al. (2003). AIB and D-aspartate were chosen as candidate amino acids because they, like taurine, are relatively resistant to metabolism by most mammalian cells and are often used in studies of this nature. L-alanine and glycine were chosen because they, like taurine, have a large intracellular/extracellular concentration ratio. L-leucine was chosen as a representative essential neutral amino acid. Briefly, cells were loaded with radiolabelled amino acids by incubating in a buffer containing (in mM): 135 $\mathrm{NaCl}, 5 \mathrm{KCl}, 2 \mathrm{CaCl}_{2}, 1 \mathrm{MgSO}_{4}, 10$ glucose and 10 TrisMOPS, pH 7.4 plus $1-2 \mu \mathrm{Ci} / \mathrm{ml}$ of radiolabelled amino acid for either $10 \mathrm{~min}$ (L-alanine, glycine, L-leucine) or $60 \mathrm{~min}$ (taurine, AIB, D-aspartate) at $37^{\circ} \mathrm{C}$. The loading buffer was aspirated and the cells were washed four times in rapid succession with a buffer similar in composition to that just described except that it contained no radioactivity. The efflux of radiolabelled amino acids from the cells was measured by the sequential addition and removal of $2 \mathrm{ml}$ of medium (see figure legends for precise details of composition) at $1 \mathrm{~min}$ intervals at $37^{\circ} \mathrm{C}$. The cells were lysed after the wash-out period by incubating in $2 \mathrm{ml}$ of distilled water for at least $3 \mathrm{~h}$. The wash-out samples and the lysate were prepared for counting by adding $10 \mathrm{ml}$ of UltimaGold liquid scintillation cocktail. The fractional efflux for each collection period was calculated according to equation (1);

$$
\text { Fractional efflux }\left(\min ^{-1}\right)=\Delta \mathrm{X} /\left(\Delta \mathrm{t} \cdot \mathrm{X}_{\mathrm{t}}\right)
$$

where $\Delta \mathrm{X}$ is the amount of radioactivity $(\mathrm{dpm})$ released from the cells in the time interval $\Delta \mathrm{t}$ and $\mathrm{X}_{\mathrm{t}}$ is the amount of radioactivity (dpm) associated with the cells at the start of each 1 min sampling period. We are of course aware that L-alanine, glycine and L-leucine, unlike taurine, AIB and $D$-aspartate could have been readily metabolized during the loading period and efflux time course. No correction has been made for this possibility. However, we sought to minimize the extent of metabolism by using a short loading period when the release of L-alanine, glycine and L-leucine was measured. Efflux time courses were also examined by plotting $\ln \left[\operatorname{amino}_{\operatorname{acid}_{\mathrm{i}}(\mathrm{t}) / \mathrm{amino}}\right.$ $\left.\operatorname{acid}_{i}(t=0)\right]$ as a function of time where amino $\operatorname{acid}_{i}(t=0)$ is the amount of radioactivity in the cells at the start of the time course and amino $\operatorname{acid}_{i}(t)$ is the amount of isotope remaining in the cells at time t. Preliminary experiments established that the efflux of radiolabelled amino acids from MDA-MB-231 and MCF-7 cells, measured under isosmotic conditions, followed first order kinetics and thus could be described by a single mono-exponential equation (results not shown). In subsequent experiments, amino acid efflux was allowed to proceed for $4 \mathrm{~min}$ prior to testing the effect of a hyposmotic shock. 


\section{Solutions}

The isosmotic solution (osmolality $=299 \mathrm{mOsm} / \mathrm{kg}$ water; range 295-307 $\mathrm{mOsm} / \mathrm{kg}$ water) contained (in $\mathrm{mM}$ ): 135 $\mathrm{NaCl}, 5 \mathrm{KCl}, 2 \mathrm{CaCl}_{2}, 1 \mathrm{MgSO}_{4}, 10$ glucose and 10 TrisMOPS, $\mathrm{pH}$ 7.4. The hyposmotic solutions were similar in composition except that they contained $75 \mathrm{mM} \mathrm{NaCl}$ and had an osmolality of $186 \mathrm{mOsm} / \mathrm{kg}$ water (range 179-192). The osmolality of the solutions was measured using a MicroOsmometer (Vitech Scientific LTD, UK). When required, ATP was dissolved directly in the isosmotic and hyposmotic buffers no more than $60 \mathrm{~min}$ prior to use.

\section{Statistics}

Results are presented as means \pm SEM. Student's paired $t$ test was used to examine the difference between two means whereas ANOVA followed by Tukey's test was used when multiple comparisons were required. Differences were considered significant when $p<0.05$.

\section{Results}

Profile of amino acid efflux from MDA-MB-231 and MCF-7 cells

The first step in the investigation was to examine the effect of cell swelling, induced by a hyposmotic challenge, on the efflux of a range of $\alpha$-amino acids. Therefore, we tested the effect of a hyposmotic shock on the efflux of AIB, L-alanine, L-leucine, glycine and D-aspartate from both MDA-MB-231 and MCF-7 cells. For comparison we also examined the effect of cell swelling on the release of taurine from both cells lines. Figure 1 shows the effect of reducing the osmolality of the incubation medium by $38 \%$ on amino acid release from MDA-MB-231 cells. Consistent with previous results we found taurine efflux to be stimulated by a hyposmotic challenge $(p<0.001)$. Cell swelling also markedly increased the efflux of glycine $(p<0.001)$, AIB $(p<0.01)$, D-aspartate $(p<$ $0.01)$ and L-alanine $(p<0.05)$ but not L-leucine. It is notable that the profiles of volume-activated AIB, glycine, L-alanine, $\mathrm{D}$-aspartate and taurine efflux were generally similar to one another with respect to activation/inactivation. Thus, the maximum response was reached within 2-3 minutes after the cells were exposed to the hyposmotic buffer. It is apparent from Fig. 1 that the volume-activated moiety of amino acid efflux from MDA-MB-231 cells was not sustained for the entire time course. Thus, the swelling-induced portion of amino acid efflux had a tendency to inactivate. Figure 2 shows the effect of a hyposmotic challenge $(-38 \%)$ on the efflux of taurine, glycine, AIB, D-aspartate, L-alanine and Lleucine from MCF-7 breast cancer cells. In accordance with earlier results, we found taurine efflux to be increased by cell swelling $(p<0.001)$. It is clear from Fig. 2 that a hyposmotic challenge also increased the efflux of glycine $(p<0.01)$, AIB $(p<0.01)$, D-aspartate $(p<0.05)$ and L-alanine $(p<0.05)$ from MCF-7 cells. In contrast, cell swelling did not increase

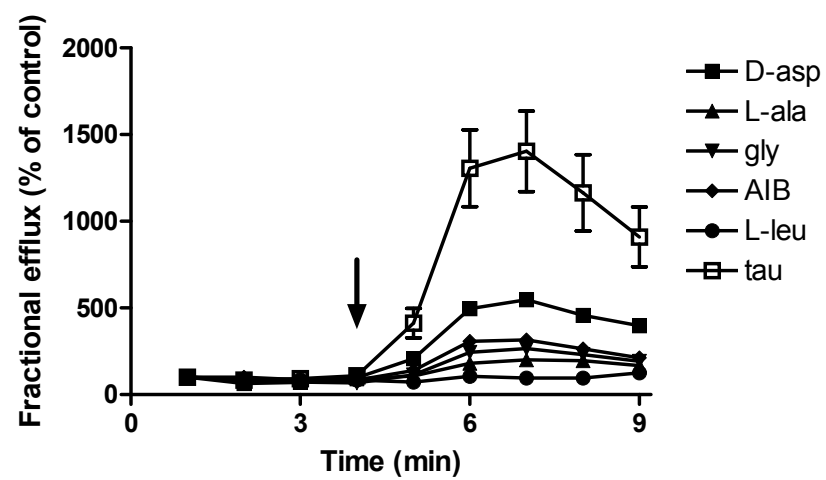

Figure 1. The effect of a hyposmotic challenge on the fractional efflux of glycine $(n=3)$, AIB $(n=4)$, D-aspartate $(n=3)$, L-alanine $(n=4)$, L-leucine $(n=4)$ and taurine $(n=5)$ from MDA-MB-231 cells. Cells were initially incubated in a medium containing (in $\mathrm{mM}$ ): $135 \mathrm{NaCl}$, $5 \mathrm{KCl}, 2 \mathrm{CaCl}_{2}, 1 \mathrm{MgSO}_{4}, 10$ glucose and 10 Tris-Mops (pH 7.4) followed by one of similar composition except that the $\mathrm{NaCl}$ concentration had been reduced to $75 \mathrm{mM}$. The arrow denotes the point in the time course when the cells were first exposed to the hyposmotic buffer. For each amino acid, the fractional efflux is expressed as a \% of control where $100 \%$ equates to the fractional release at $\mathrm{t}=1 \mathrm{~min}$.

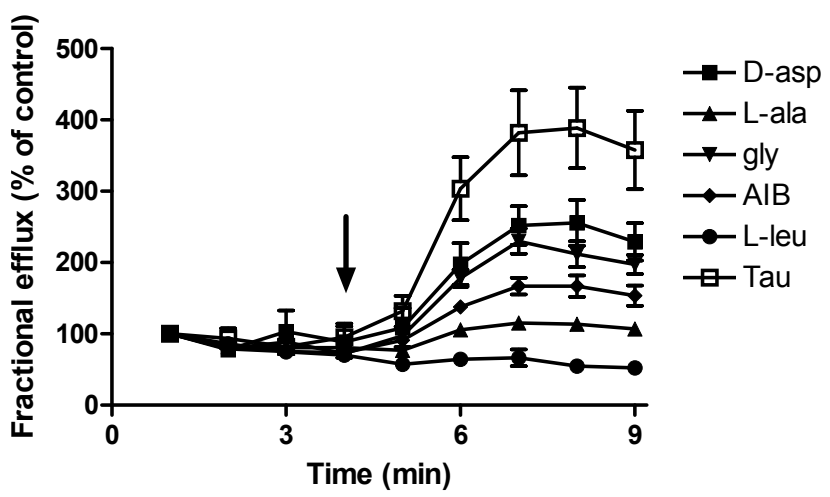

Figure 2. The effect of a hyposmotic challenge on the fractional efflux of glycine $(n=4)$, AIB $(n=4)$, D-aspartate $(n=3)$, L-alanine $(n=3)$, L-leucine $(n=4)$ and taurine $(n=6)$ from MCF-7 cells. The composition of the isosmotic and hyposmotic buffers was the same as those described in Fig. 1. The arrow denotes the point when the cells were first exposed to the hyposmotic buffer. For each amino acid, the fractional efflux is expressed as a $\%$ of control where $100 \%$ equates to the factional efflux at $\mathrm{t}=1 \mathrm{~min}$. 

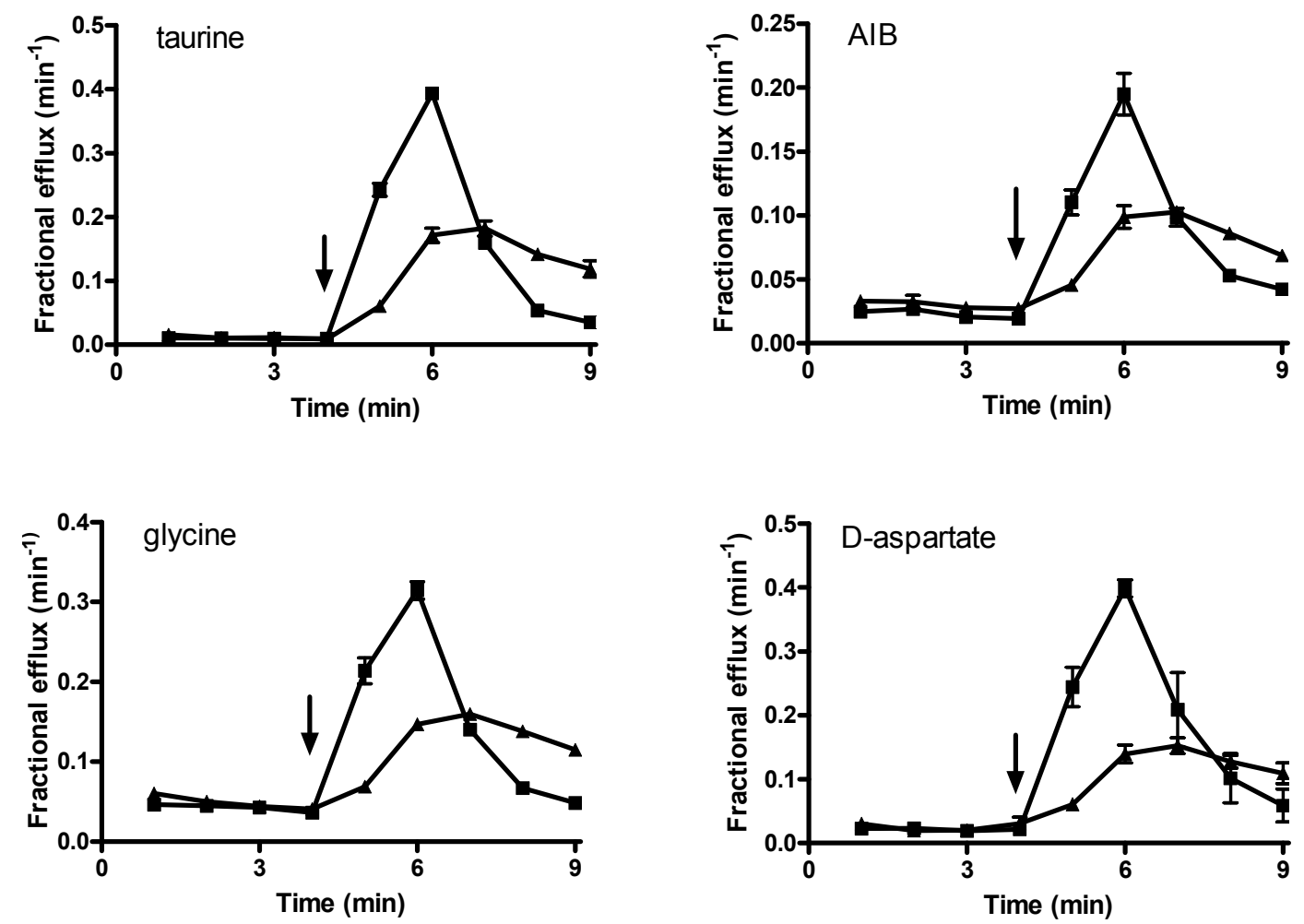

Figure 3. The effect of a hyposmotic challenge in the absence $(\boldsymbol{\Delta})$ and presence $(\boldsymbol{\square})$ of extracellular ATP on the efflux of taurine $(n=3)$, AIB $(n=3)$, glycine $(n=3)$ and D-aspartate $(n=3)$ from MDA-MB-231 cells. The composition of the isosmotic and hyposmotic buffers was the same as that described in Fig. 1. The arrow denotes the point when the cells were first exposed to the hyposmotic buffer. ATP, when required, was added to the hyposmotic buffer to give a final concentration of $100 \mu \mathrm{M}$.

the efflux of L-leucine from MCF-7 cells. Again the profiles of volume-sensitive amino acid efflux were similar to one another with the peak response being reached 3 min after the cells were exposed to the hyposmotic solution. There was a lag phase of approximately 1 min following the hyposmotic shock before amino acid efflux was significantly stimulated.

\section{The effect of ATP on swelling-induced amino acid release}

We have previously shown that volume-activated taurine efflux from MDA-MB-231 cells is markedly enhanced by ATP (Shennan et al. 2006). In view of this we tested the effect of ATP on swelling-induced AIB, glycine and D-aspartate efflux from MDA-MB-231 cells. For comparison we also examined the effect of ATP on volume-activated taurine release. In accordance with our previous results, ATP $(100 \mu \mathrm{M})$ significantly enhanced $(p<0.001)$ swelling-induced taurine release (Fig. 3). ATP also enhanced volume-activated AIB $(p<0.001)$, glycine $(p<0.001)$ and D-aspartate efflux $(p<0.001)$ from MDA-MB-231 cells (Fig. 3). Although ATP enhanced the peak response it is evident that the nucleotide inactivated volume-sensitive amino acid efflux in the latter part of the time courses. In addition, ATP had no effect on AIB efflux under isosmotic conditions (results not shown).

Volume-sensitive taurine release from MCF-7 cells is not increased by the addition of exogenous ATP (Shennan et al. 2006). We now show that swelling-induced glycine efflux is also unaffected by ATP (Fig. 4). However, volume-activated D-aspartate efflux from MCF-7 cells was slightly increased $(p<0.05)$ in the presence of ATP (Fig. 4).

\section{Inhibition of volume-activated AIB efflux by diiodosalicylate}

Swelling-induced taurine efflux from MDA-MB-231 cells is inhibited by a number of ion channel blockers including diiodosalicylate (Shennan et al. 2006). Therefore, we examined the effect of diiodosalicylate on volume-sensitive AIB efflux from MDA-MB-231 cells. Diiodosalicylate markedly reduced $(p<0.001)$ swelling-induced AIB release (Fig. 5). The effect of diiodosalicylate appears to be relatively specific for the volume-activated moiety of efflux as it had no effect on AIB release under isosmotic conditions. 
The effect of tamoxifen on volume-sensitive taurine release

It has been reported that tamoxifen inhibits volume-activated taurine release from some but not all cell types (see Shennan 2008). Curiously the effect of tamoxifen has not been examined on taurine release from human breast cancer cells despite the fact it is a widely used therapeutic agent for the treatment of estrogen-receptor positive breast cancer. Tamoxifen $(10 \mu \mathrm{M})$ inhibited volume-sensitive taurine efflux from both MDA-MB-231 and MCF-7 cells $(p<0.001)$ but had no effect on taurine release under isosmotic conditions (Fig. 6).

\section{Discussion}

An increase in cell volume stimulates the efflux of taurine from cultured human breast cancer cell lines (Shennan et al. 2006). Similarly, an increase in the cellular hydration state, induced by a hyposmotic shock, also induces the release of AIB, L-alanine, D-aspartate and glycine from MCF-7 and MDA-MB-231 cells. The major question is: do the $\alpha$-amino
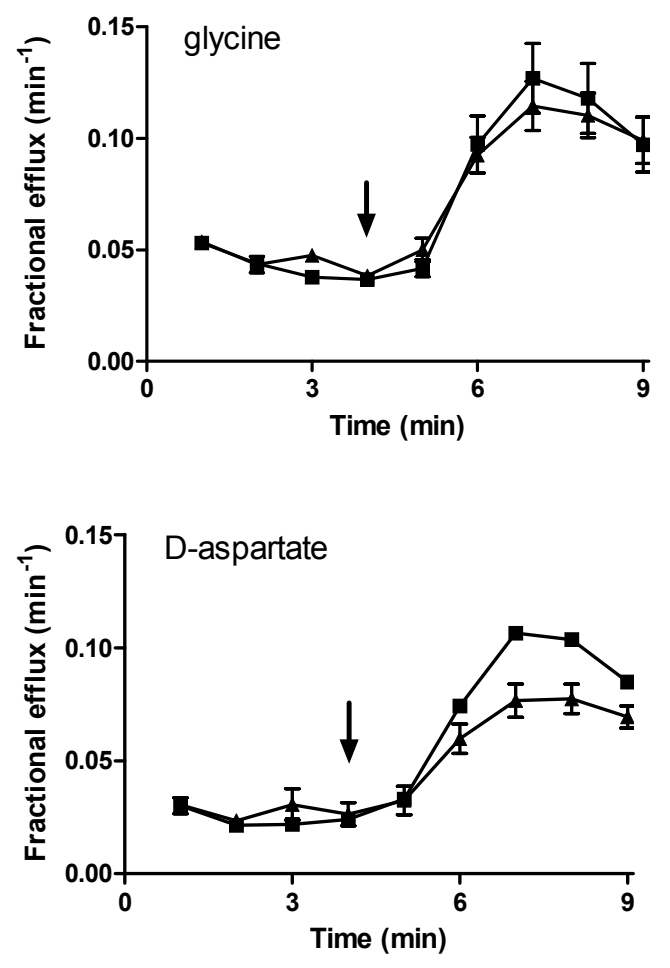

Figure 4. The effect of a hyposmotic challenge in the absence $(\boldsymbol{\Delta})$ and presence $(\boldsymbol{\square})$ of extracellular ATP on the efflux of glycine $(n=4)$ and D-aspartate $(n=3)$ from MCF-7 cells. The composition of the isosmotic and hyposmotic buffers was the same as those described in Fig. 1 . The arrow denotes the point when the cells were first exposed to the hyposmotic buffer. ATP, when required was added to the hyposmotic buffer to give a final concentration of $100 \mu \mathrm{M}$.

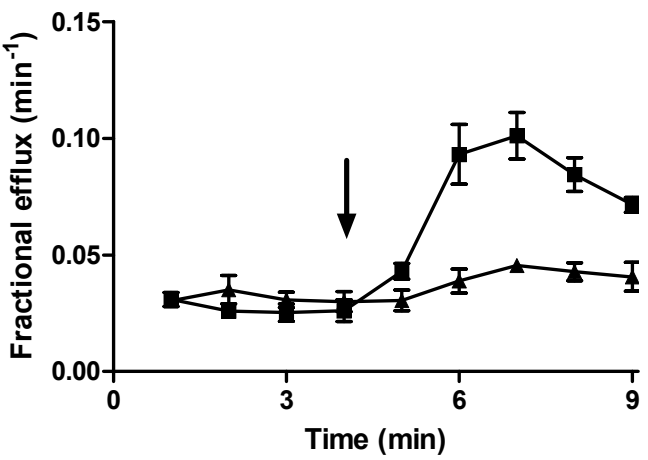

Figure 5. The effect of a hyposmotic shock in the absence ( $\boldsymbol{\square})$ and presence $(\boldsymbol{\Delta})$ of diiodosalicylate on the efflux of AIB $(n=4)$ from MDA-MB-231 cells. The composition of the isosmotic and hyposmotic buffers was the same as those described in Fig. 1. Diiodosalicylate, when required, was present throughout the entire time course at a final concentration of $1 \mathrm{mM}$.

acids share the same transport system as taurine? There is prima facie evidence that the answer is yes as volume-activated taurine and $\alpha$-amino acid efflux within each cell line have similar properties.

Comparison between volume-activated taurine and $\alpha$-amino acid release from $M D A-M B-231$ cells

Volume-activated efflux time-courses should be similar if a common pathway exists (Stutzin et al. 1999; Shennan 2008). The profiles of swelling-activated taurine, AIB, L-alanine, D-aspartate and glycine acid efflux from MDA-MB-231 cells were similar with respect to activation and inactivation. However, cell swelling did not increase the efflux of each amino acid to the same extent. Thus a hyposmotic shock stimulated amino acid efflux in the order of taurine $>$ glycine $=\mathrm{D}$-aspartate $>\mathrm{AIB}=\mathrm{L}$-alanine. The pathway is relatively selective since a hyposmotic challenge did not increase the efflux of L-leucine from MDA-MB-231 cells.

It has been suggested, on the basis of pharmacological inhibition, that volume-activated amino acid efflux utilises volume-activated anion channels (e.g. see Kirk 1997). Cell swelling increases the efflux of the anionic amino acid Daspartate from MDA-MB-231 cells and thus lends support for this view. In this connection, a hyposmotic challenge increases the efflux of $\mathrm{Cl}^{-}\left(\mathrm{I}^{-}\right)$from MDA-MB-231 cells (Shennan et al. 2006). However, the profiles of swellinginduced $\mathrm{Cl}^{-}\left(\mathrm{I}^{-}\right)$efflux is markedly different from those of $D$-aspartate and the other $\alpha$-amino acids suggesting the presence of separate pathways.

The volume-sensitive efflux of $\alpha$-amino acids from MDAMB-231 cells is stimulated by ATP in a similar fashion to that of taurine efflux. The time-course of swelling-induced 

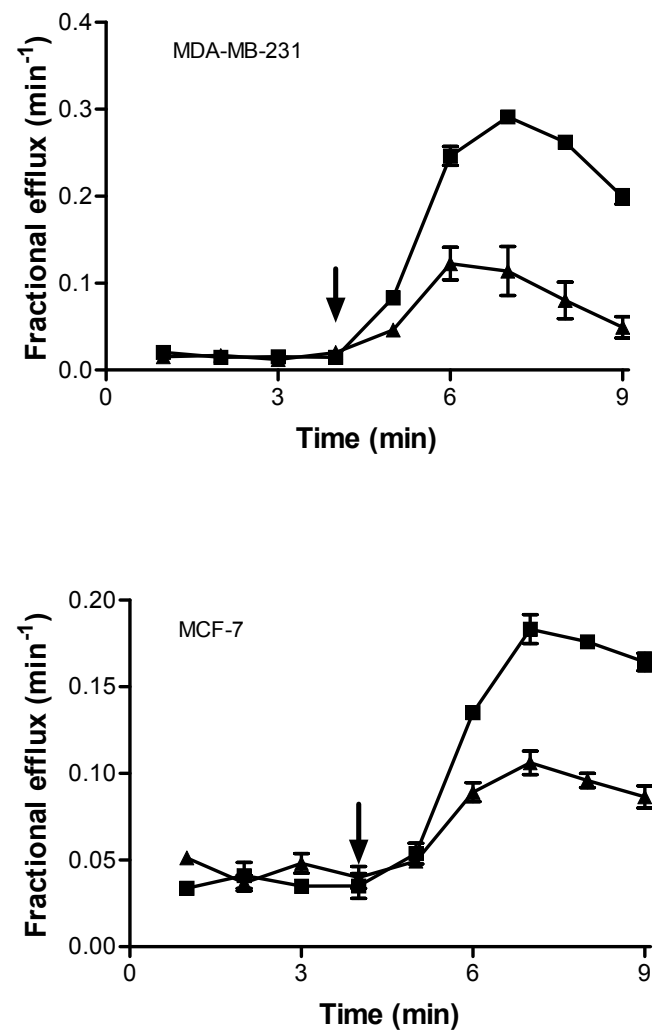

Figure 6. The effect of a hyposmotic challenge in the absence ( $\boldsymbol{\square})$ and presence $(\mathbf{\Delta})$ of tamoxifen on taurine efflux from MDA-MB231 and MCF-7 cells $(n=5)$. The composition of the isosmotic and hyposmotic buffers was the same as those described in Fig. 1. Tamoxifen, when required was present throughout the entire time course at a final concentration of $10 \mu \mathrm{M}$.

release of $\mathrm{D}$-aspartate, glycine, AIB and taurine, in the presence of ATP, was similar with respect to both activation and inactivation. This is further evidence of a shared pathway. Diiodosalicylate inhibits both volume-activated taurine and AIB efflux from MDA-MB-231 cells which is consistent with a shared pathway.

Comparison between volume-activated taurine and $\alpha$-amino acid efflux from MCF-7 cells

A hyposmotic shock increased the efflux of AIB, glycine, L-alanine and D-aspartate from MCF-7 cells in a manner similar to taurine efflux. As with MDA-MB-231 cells, a hyposmotic challenge did not increase the efflux of each amino acid from MCF-7 cells to the same extent: cell swelling increased amino acid efflux in the order of taurine $=$ glycine $>\mathrm{D}$-aspartate $>\mathrm{AIB}=\mathrm{L}$-alanine. The pathway in MCF-7 cells, like the one present in MDA-MB-231 cells, is relatively selective since cell swelling had no effect on the release of L-leucine.
Unlike MDA-MB-231 cells, there was no effect of ATP on the volume-activated release of $\alpha$-amino acids from MCF-7 cells. This is consistent with our previous result showing ATP to have no effect on the release of taurine from MCF-7 cells. This set of observations adds weight to the argument for the existence of a common pathway for taurine and $\alpha$ amino acids. However, ATP had a small but significant effect on volume-activated D-aspartate release. Swelling-induced D-aspartate efflux from MCF-7 cells may utilize a separate pathway from the other amino acids or alternatively there may be more than one volume-activated D-aspartate efflux pathway one of which is enhanced by extracellular ATP. More experiments are needed to resolve this issue.

\section{Physiological significance of volume-activated amino acid efflux and the effect of tamoxifen}

Human breast cancer cells release $\mathrm{K}^{+}$and $\mathrm{Cl}^{-}$when exposed to a hyposmotic shock (Horton et al. 1998; Marin et al. 2005; Gow et al. 2005; vanTol et al. 2007; Roy et al. 2008). It is envisaged that the release of these two ions coupled to the efflux of water allow cells to regulate their volume. Indeed, a RVD is predicted to be mostly due to the efflux of $\mathrm{K}^{+}$and $\mathrm{Cl}^{-}$because of their relatively large intracellular concentrations. However, most cells, including breast tumour cells, have a relatively large intracellular pool of taurine and $\alpha$ amino acids. Therefore the findings from this study suggest that volume-sensitive amino acid efflux may act in parallel with $\mathrm{K}^{+}$and $\mathrm{Cl}^{-}$efflux to bring about a RVD.

Although the results support the notion for $\alpha$-amino acids and taurine utilizing a common volume-activated efflux pathway in human breast cancer cells they also reinforce the view that the volume-sensitive amino acid efflux pathway or its regulation differs between the two cell lines (see Shennan et al. 2006). The differential effect of extracellular ATP on amino acid release exemplifies this point. However, at present, we are unable to offer an explanation as to why the properties of volume-sensitive amino acid efflux should differ between the two cell lines other than the possibility they may have different patterns of purinergic receptor expression.

The present study serves as a basis to further investigate the properties of volume-activated solute transport mechanisms in human breast cancer cells. Identification of the pathways involved at the molecular level will be a step towards developing strategies aimed at controlling the rate of proliferation and/or apoptosis of human breast cancer cells. In this connection it is interesting to note that tamoxifen inhibited volume-activated taurine efflux from both MDA-MB-231 and MCF-7 cells suggesting the effect is independent of the estrogen receptor. Tamoxifen may, in part, exert its effect on the growth of breast cancer cells by affecting volume-activated transport processes. In this connection, tamoxifen methiodide, in parallel to inducing 
growth arrest, increased the volume of MCF-7 breast tumours implanted orthotopically in immunodeficient mice (Paran et al. 2004).

Acknowledgement. This work was funded by the Scottish Executive Environment and Rural Affairs Department.

\section{References}

Brodzki A., Pasternak K., Balicki I., Brodzki P., Szponder T., Tatara M. R. (2004): Concentration of free amino acids in mammary gland tumors in dogs. Med. Weter. 60, 937-941

Gow I. F., Thomson J., Davidson J., Shennan D. B. (2005): The effect of a hyposmotic shock and purinergic agonists on $\mathrm{K}^{+}$ $\left(\mathrm{Rb}^{+}\right)$efflux from cultured human breast cancer cells. Biochim. Biophys. Acta 1712, 52-61 doi:10.1016/j.bbamem.2005.04.002

Häussinger D. (1996): The role of cellular hydration in the regulation of cell function. Biochem. J. 313, 697-710

Hoffmann E. K., Lambert I. H., Pedersen S. F. (2009): Physiology of cell volume regulation in vertebrates. Physiol. Rev. 89, 193-277 doi:10.1152/physrev.00037.2007

Hoffmann E. K., Simonsen L. O. (1989): Membrane mechanisms in volume and $\mathrm{pH}$ regulation in vertebrate cells. Physiol. Rev. 69, 315-382

Horton J., Vanoye C. G., Reuss L. (1998): Swelling-activated chloride currents in a drug-sensitive cell line and a P-glycoprotein-expressing derivative are underlied by channels with the same pharmacological properties. Cell. Physiol. Biochem. 8, 246-260 doi:10.1159/000016287

Huxtable R. J. (1992): Physiological actions of taurine. Physiol. Rev. 72, 101-163

Kao Y. Y., Liu K. T., Huang M. F., Chiu T. C., Chang H. T. (2010): Analysis of amino acids and biogenic amines in breast cancer cells by capillary electrophoresis using polymer solutions containing sodium dodecyl sulphate. J. Chromat. A 1217, 582-587 doi:10.1016/j.chroma.2009.11.069

Kirk K. (1997): Swelling-activated organic osmolyte channels. J. Membr. Biol. 158, 1-16 doi:10.1007/s002329900239

Lang F., Busch G. L., Ritter M., Volkl H., Waldegger S., Gulbins E., Haussinger D. (1998): Functional significance of cell volumeregulatory mechanisms, Physiol. Rev. 78, 247-306

Maeno E., Ishizaki Y., Kaneseki T., Hazama A., Okada Y. (2000): Normotonic shrinkage because of disordered volume regulation is a prerequisite to apoptosis. Proc. Natl. Acad. Sci. U.S.A. 97, 9487-9492 doi:10.1073/pnas.140216197

Marin M., Poret A., Maillet G., Leboulenger F., Le Foll F. (2005): Regulation of volume-sensitive Cl- channels in multi-drug resistant cells. Biochem. Biophys. Res. Commun. 324, 1266-1278 doi:10.1016/j.bbrc.2005.07.010

Millar I. D., Barber M. C., Lomax M. A., Travers M. T., Shennan D. B. (1997): Mammary protein synthesis is acutely regulated by the cellular hydration state. Biochem. Biophys. Res. Commun. 230, 351-355 doi:10.1006/bbrc.1996.5959

Paran Y., Bendel P., Margalit R., Degani H. (2004): Water diffusion in the different microenvironment of breast cancer. NMR Biomed. 17, 170-180 doi: $10.1002 / \mathrm{nbm} .882$

Pine M. J., Kim U., Ip C. (1982): Free amino acid pools of rodent mammary tumours. J. Natl. Cancer Inst. 69, 729-735

Roy J., Vantol B., Cowley E. A., Blay J., Linsdell P. (2008): Pharmacological separation of hEAG and hERG $\mathrm{K}^{+}$channel function in the human mammary carcinoma cell line MCF-7. Oncol. Rep. 19, 1511-1516

Shennan D. B., Thomson J., Barber M. C., Travers M. T. (2003): Functional and molecular characteristics of system $\mathrm{L}$ in human breast cancer cells. Biochim. Biophys. Acta 1611, 81-90 doi:10.1016/S0005-2736(03)00028-2

Shennan D. B., Thomson J., Gow I. F. (2006): Osmoregulation of taurine efflux from cultured human breast cancer cells: comparison with volume activated $\mathrm{Cl}^{-}$efflux and regulation by extracellular ATP. Cell. Physiol. Biochem. 18, 113-122 doi:10.1159/000095178

Shennan D. B. (2008): Swelling-induced taurine transport: relationship with chloride channels, anion-exchangers and other swelling-activated transport pathways. Cell. Physiol. Biochem. 21, 15-28 doi:10.1159/000113743

Stutzin A., Torres R., Oporto M., Pachero P., Eguiguren A. L., Cid L. P., Sepulveda F. V. (1999): Separate taurine and chloride efflux pathways activated during regulatory volume decrease. Am. J. Physiol. 277, C392-402

Stutzin A., Hoffmann E. K. (2006): Swelling-activated ion channels: functional regulation in cell swelling, proliferation and apoptosis. Acta Physiol. 187, 27-42 doi:10.1111/j.1748-1716.2006.01537.x

Trimarchi J. R., Lui L, Smith P. J. S., Keefe D. L. (2002): Apoptosis recruits two-pore domain potassium channels used for homeostatic volume regulation. Am. J. Physiol. Cell. Physiol. 282, C588-594

vanTol B. L., Missan S., Crack J., Moser S., Baldridge W. H., Linsdell P., Cowley E. A. (2007): Contribution of KCNQ1 to the regulatory volume decrease in the human mammary epithelial cell line MCF-7. Am. J. Physiol. 293, C1010-1019 doi:10.1152/ajpcell.00071.2007

Received: May 24, 2010

Final version accepted: October 8, 2010 